\title{
El repertorio de protesta de la sociedad civil a través de la prensa en la transición democrática española
}

\author{
Sandra MÉndez Muros \\ Universidad de Sevilla \\ sanmenmur@us.es
}

\section{Resumen:}

Este artículo presenta un estudio del repertorio de la protesta empleado por la sociedad civil durante la transición democrática española. Tomando como eje el valor/noticia del repertorio en dos medios de prensa privada publicada en Sevilla entre noviembre de 1975 y junio de 1977, nos servimos del análisis de contenido para observar sectores sociales, formatos y niveles de conflictividad. Concluimos que la progresiva reorientación de la protesta mediatizada hacia el diálogo y el asociacionismo es un claro ejemplo de complementariedad entre la sociedad civil y la prensa en el proceso de cambio.

Palabras clave: Sociedad civil; transición democrática española; prensa; repertorio de protesta

\section{The protest repertoire of the civil society through the press in the Spanish democratic transition}

\begin{abstract}
:
This paper presents a study on the protest repertoire used by the civil society during the Spanish democratic transition. Taking as axis the value/news of the repertoire on two private media published in Seville between November 1975 and June 1977, we use the content analysis to focus on social sectors, formats and levels of conflict. We conclude that the progressive reorientation of the mediated protest towards the dialogue and the partnership is a clear example of complementarity between the civil society and the press in the change process.
\end{abstract}

Key words: Civil society; Spanish democratic transition; press; protest repertoire

\section{Referencia normalizada:}

Méndez Muros, S. (2014): El repertorio de protesta de la sociedad civil a través de la prensa en la transición democrática española. Historia y Comunicación Social. Vol. 19. Núm. Especial Enero. Págs. 303-313.

Sumario: 1. La sociedad civil durante la transición: ¿desmovilización o resurgimiento? 2. La protesta como expresión de la sociedad civil. 3. Mediación de la prensa y mediatización de la protesta: los repertorios. 4. Objetivo y método. 5. Cristalización de la protesta social en la prensa. 5.1. El flujo informativo. 5.2. La especialización sectorial. 5.3. Los formatos del repertorio. 5.4. Niveles de conflictividad. 6. A modo de conclusión. 7. Referencias bibliográficas. 


\section{La sociedad civil durante la transición: ¿Desmovilización o resurgimiento?}

El modélico ejemplo de la transición española, exportado internacionalmente en los años ochenta y noventa del siglo XX, ha desatendido en parte la acción de los actores no políticos que intervinieron en ella (O’Donnel y Schmitter, 1986: 6). Dos han sido básicamente las interpretaciones que desde los estudios históricos y sociológicos han primado sobre la acción de los actores no políticos, sobre los que se sustentan dos argumentos que explican el éxito de la transición: el resurgimiento o la desmovilización de la sociedad civil. Ambas posturas se basan en la ausencia o presencia entre los españoles de una cultura democrática y el grado de influencia de la protesta social en las decisiones tomadas por la clase política.

La ausencia de una cultura democrática entre los españoles respalda las posiciones afines a la desmovilización ciudadana en los primeros años de la transición. Los ciudadanos son testigos pasivos de los principales fermentos del proceso democrático, según concibe el sociólogo López Pintor (1982: 80). El historiador Palacio Atard (1989: 48-49) niega, por su parte, que la movilización ciudadana se impusiera a la fuerza del rey y de los políticos reformistas, dado que no "ocasionaron grandes quebraderos de cabeza a los gobernantes", si bien un 55\% de los españoles reconoce en un sondeo sobre los orígenes de la transición llevado a cabo a mitad de la década de los ochenta que ésta no habría sido posible sin la presión ciudadana (Pérez Ledesma, 2006: 126). La creciente politización de la vida española es claramente compartida por los historiadores que defienden la existencia de una cultura democrática durante el proceso de transición, resultando vital el peso de algunos sectores políticamente formados (Preston, 1986: 96).

La noción regeneradora convive con la de la desmovilización durante la última década del siglo XX. Ciertas tesis sociológicas defienden un rol activo popular durante el proceso de transición, amparándose en la idea de que el derrumbe interno y la crisis del régimen franquista no habrían acarreado por sí solos la democratización (Köhler, 1995: 80). La obra de Pérez Díaz (1987) expone de forma más rotunda el concepto del retorno de la sociedad civil. Linz (1992: 435-436) mantiene entretanto la inexistencia de una crisis profunda de la dictadura a la muerte de Franco, muy al contrario, ésta presenta estabilidad y, de cualquier forma, no son las condiciones estructurales e históricas las que determinan el futuro de una naciente democracia sino las acciones de los gobernantes.

Se desarrolla entonces la creencia de que la desmovilización ciudadana auspicia en cierto modo el cambio democrático. La sociedad española no se moviliza ni por la democracia ni por el mantenimiento del régimen y deja "exclusivamente en manos de los políticos la resolución del problema que se plantea España en el año 1975", argumenta el sociólogo Cayo Sastre (1997: 65), quien agrega que la desmovilización favorece la estrategia de cambio diseñada por las élites políticas (Sastre García, 1997: 43). De manera simultánea, numerosos historiadores alegan la existencia de una cultura política pro democratizadora que se apoya en el desarrollo socioeconómico que, desde el acceso a la formación y la libertad de expresión, acaba con la docilidad 
política originada por el analfabetismo (Seco Serrano, 1991: 252), además de promover las corrientes opositoras en los sectores más instruidos (obreros, universitarios, profesionales, etc.) y contribuir a la difusión del conocimiento de las libertades del entorno europeo (Aróstegui, 2000: 22).

Más recientemente, los estudios históricos se centran en el protagonismo ciudadano en la conquista de la democracia (Quirosa-Cheyrouze, 2011), aunque apuntan al desgaste de la dictadura motivado por las presiones estudiantiles, obreras y vecinales, entre otras, que ponen en entredicho la conservación del régimen a la muerte de Franco (Carrillo-Linares, 2006: 169) y señalan que la destreza de los políticos reformistas se manifiesta más a la hora de interpretar las "señales procedentes desde abajo, desde una sociedad civil crecientemente movilizada y demandante de nuevas y mayores libertades políticas" que en el hecho de dirigir los acontecimientos (Martín García, 2010: 140-144).

\section{La protesta como expresión de la sociedad civil}

La sociedad civil en democracia es considerada como el espacio donde los poderes sociales se forman y entran en conflicto para institucionalizarse (Attili Card Amone, 2004: 145). López Cantos (2006) apoya el concepto de democracia en una teoría del conflicto entre intereses grupales contrapuestos. En el estudio de la sociedad civil, la acción colectiva es el indicador fundamental, el cual se materializa mediante el conflicto que reconoce la discrepancia y organización de un colectivo social. A su vez, el conflicto toma forma en distintos modos de protesta, siendo ésta el instrumento de expresión primordial de los ciudadanos.

En este sentido, las tesis que defienden el resurgimiento de la ciudadanía o la desmovilización disienten en la influencia en la agenda de decisiones políticas de la contestación social durante el proceso de transición, tanto en la presión para lograr reformas democratizadoras como en términos de deslegitimación del poder político instaurado y de la incapacidad de los gobernantes.

Entre las causas que explican la efectividad de la protesta se encuentran su propia existencia en el terreno de la ilegalidad, su progresiva duración a partir del año 1976, el aumento de la crisis de legitimidad y la facilidad para crear incertidumbre en el régimen (Soto, 1998: 151), a lo que se suma su papel activo en las negociaciones llevadas a cabo por los partidos políticos (Tusell y Soto, 1996: 378), originando una cada vez más aguda tensión sociopolítica, y la conflictiva imagen internacional de España recogida en los informes diplomáticos de otros países (Martín García, 2010: 139).

Las razones que llevan a hablar de despolitización de la sociedad y de exigua influencia de la reprobación ciudadana están sujetas al carácter represor de la dictadura que soslaya la formación de un gran movimiento social (Saz Campos, 2010: 
78-79). Las manifestaciones son advertidas con desconfianza porque perturban la relación cordial entre el Estado y la sociedad (Jaime-Jiménez y Reinares, 1998: 166-187). Asimismo, los delitos que subvierten los principios básicos del Estado, que alteran el orden público o agitan la conciencia nacional son castigados por el Tribunal de Orden Público (TOP).

\section{Mediación de la prensa y mediatización de la protesta: Los repertorios}

Si atendemos a que la opinión pública está condicionada por los medios de comunicación de masas, para que un sistema político adquiera legitimidad es preciso que exista flujo comunicativo de la sociedad civil (Habermas, 1998: 432). El proceso unidireccional de toma de decisiones es suplido por la idea del círculo hermenéutico o "dinámica circular de ida y vuelta", originando que se forme una voluntad democrática común donde la opinión pública legitima las decisiones colectivas en última instancia (De Zan, 2006).

El progresivo relajamiento de la censura tras la promulgación de la Ley de Prensa e Imprenta de 1966 incita a una actitud periodísticamente más activa, alejada de la política comunicativa ejercida durante el franquismo, que genera una sociedad exenta de estímulos participativos. Desde los últimos años de la dictadura, los medios de comunicación exponen, por una parte, la acción transformadora de los actores sociales y la quiebra de la imagen de un país sin problemas de orden público (Barrera, 1995: 19) y, por otra, se descubren como un agente mediador del proceso, conectando las demandas del ambiente social y las corrientes de decisiones del sistema político (Gomis, 1987: 308-310). En este proceso de mediación de la prensa se sitúa la mediatización de la protesta, concebida como el formato con el que los actores exhiben en la calle el conflicto en el que están inmersos, pero que se conforma como acontecimiento noticiable que adquiere mayor efecto en los medios de comunicación. De este modo, la contestación ciudadana se compone en la escena pública de la protesta manifestada en la realidad de la calle y en la realidad mediática.

Algunos sociólogos históricos se basan en las reivindicaciones que motivan la protesta para tipificarla y comprenderla, por ejemplo, se catalogan las manifestaciones como gremiales, políticas, estudiantiles y culturales. Otros autores como Charles Tilly (1978) y Sidney Tarrow (2004) prefieren referirse a las propias pautas culturales con las que cuenta cada sociedad para expresar su desacuerdo dependiendo del contexto. Son los denominados 'repertorios' de acción colectiva o conjuntos factibles de alternativas ensayadas que han evolucionado desde el más antiguo catálogo que avista formas locales, directas, violentas y rígidas como la destrucción de maquinaria, los motines religiosos o la quema de cosechas y el más actualizado que recoge movilizaciones nacionales, indirectas, pacíficas y flexibles como las manifestaciones, las huelgas o los mítines y cuyos resultados son más efectivos en la llamada de aten- 
ción y en la negociación. En cualquier caso, las particularidades del conflicto fijan la forma en que funciona el repertorio de protesta.

\section{Objetivo y método}

Nuestro principal objetivo es conocer el repertorio de protesta empleado por la sociedad civil durante la transición democrática española a través de la prensa toda vez que consideramos que el asentado rol mediador de ésta está directamente conectado con su tarea de mediatización de la protesta ciudadana. La motivación se encuentra en la ausencia de interpretaciones -hasta ahora exclusivamente suscitadas por historiadores y sociólogos- por parte de los historiadores de la comunicación sobre el cometido que ejerce la sociedad civil durante el proceso de cambio y sobre el rol que asume la prensa a la que se le asigna una exclusiva función resocializadora de la ciudadanía para reconocer la legitimidad del sistema democrático y asumir las nuevas fórmulas actitudinales.

Hemos seleccionado dos medios locales de Sevilla pertenecientes a la empresa privada, Abc de Sevilla y El Correo de Andalucía, que reclaman niveles más altos de libertad y desarrollo político al contrario de la prensa oficial (Sinova, 1989: 262) y que amasan una difusión total de más de 85.500 lectores entre 1976 y 1977. Hemos llevado a cabo un análisis de contenido de los textos sobre el valor/noticia de la reivindicación ciudadana, publicados entre noviembre de 1975 y junio de 1977 y divididos bimestres. Asimismo, nos hemos servido de un análisis micro-social que toma como muestra la sociedad civil sevillana dividida en cinco sectores: obrero, estudiantil, vecinal, cultural-artístico y ciudadano. Desde parámetros cuantitativos univariables y bivariables, estudiamos el flujo noticioso, la especialización sectorial, los formatos del repertorio (manifestaciones, huelgas, discursos y asociaciones) y los niveles de conflictividad en función del grado de alteración del orden público: nivel A $\mathrm{o}$ alto (manifestaciones y huelgas) y nivel B o bajo (discursos y asociaciones).

\section{Cristalización de la protesta social en la prensa}

\subsection{El flujo informativo}

El primer resultado destacable es que el bimestre enero-febrero de 1976 se presenta como el de mayor flujo informativo de la contestación ciudadana en la prensa con un $26,34 \%$, lo que permite referirnos a una explosión reivindicativa que llega a duplicar el segundo porcentaje más elevado (13,32\%), conseguido en marzo-abril de 1976. La acción reivindicativa tiende a un progresivo decrecimiento a partir de esta fecha y solamente en los meses de enero-febrero de 1977 con un 12,20\% vuelve a obtener el grado contestatario de los primeros meses de la transición, localizándose una segunda 
ola de discrepancia. Los bimestres que menor número de protestas contienen son los que enmarcan el principio (noviembre-diciembre de 1975 con un 6,10\%) y final (mayo-junio de 1977 con un 4,77\%) del período de análisis.

Con un $48,32 \%$ el sector obrero se erige el principal generador de la protesta, secundado por el sector estudiantil (27,46\%), ciudadano (12,41\%), cultural-artístico $(6,61 \%)$ y vecinal $(5,18 \%)$. Los meses en los que el sector obrero se presenta más agitado son enero y febrero de 1976 (33,05\%), seguidos de marzo y abril de 1976 $(13,47 \%)$, a partir de los cuales se inicia un considerable declive donde no llega a lograr el 9\% e, incluso, se reduce a la mitad. En el bimestre enero-febrero de 1976 $(24,07 \%)$ también se acoge la mayor parte de la reprensión estudiantil, que adquiere el segundo dato más importante un año después, en enero-febrero de 1977 (20,37\%). En el bimestre septiembre-octubre de $1976(15,68 \%)$ y en el de enero-febrero de 1977 (19,60\%) figura con mayor asiduidad en los diarios el sector vecinal, mientras que el sector cultural-artístico se presenta en mayor proporción en los meses de enero y febrero del año 1976 (32,30\%) y del año 1977 (30,76\%). La disconformidad ciudadana se extiende de modo más amplio en marzo-abril de 1976 (14,75\%), siendo particularmente beligerante en julio-agosto del mismo año (19,67\%). La considerable bajada que experimenta en los meses siguientes hace que no supere el $10 \%$ y logra su dato mínimo en mayo-junio de 1977.

\subsection{La especialización sectorial}

El hecho de que un sector destaque sobre el resto de sectores en ciertos momentos del análisis nos permite observar si la protesta por la demanda democrática presenta un determinado carácter según se trate de un sector concreto o del conjunto de la ciudadanía, así como conocer qué actores sociales son los que la prensa apunta como agentes activos del proceso. Desde el punto de vista periodístico, en todo el período de análisis el sector obrero es el principal promotor de la reprensión con un 48,32\%, seguido del estudiantil $(27,46 \%)$, del ciudadano $(12,41 \%)$, del cultural/artístico $(6,61 \%)$ y del vecinal $(5,18 \%)$. Por meses, los resultados señalan que noviembre-diciembre de 1975 y durante 1976 se mantiene el esquema general de jerarquización de sectores, siendo claramente el obrero el sector que encabeza las acciones de protesta. De esta forma, un 60,61\% convierten el bimestre enero-febrero de 1976 en el de mayor auge; hasta los meses de otoño el valor ronda el $50 \%$ cuando se da paso a una disminución (35,71\%) que al final del año logra mejorar.

Tras el obrero, el sector estudiantil ocupa la segunda posición con datos irregulares en torno al $25-30 \%$ que experimenta el silencio del período estival $(5,55 \%)$ y una potente irrupción como sector líder en los meses de septiembre y octubre (40,47\%) para recuperar al finalizar el año 1976 los valores iniciales. El sector vecinal es el último en hacer su aparición en la prensa y lo hace de forma dubitativa y gradual consiguiendo hasta los meses de julio y agosto de 1976 un 4\% y doblando contundentemente su presencia a partir de otoño con un 9,52\%. La reivindicación del sector cultural-artístico contempla el mismo cariz minoritario y tímido que el vecinal siendo más incisivo en los meses de enero y febrero y de noviembre y diciembre de 1976, 
donde obtiene un $8,10 \%$ y un $7,05 \%$, respectivamente. Más activo e incesante se muestra el sector ciudadano con valores sobre el $14 \%$ a medida que se suceden los meses, asumiendo una notable relevancia en julio y agosto de 1976 con un 33,33\%.

El esquema jerárquico se ve modificado en enero-febrero de 1977. El sector estudiantil gana terreno $(45,83 \%)$, duplicando su habitual cota, y crece el sector cultural-artístico $(16,66 \%)$, en detrimento del sector obrero $(20,83 \%)$, que recupera liderazgo cuando vuelve a lograr sus acostumbrados datos del $50 \%$ en los siguientes meses. En marzo-abril, el sector estudiantil se posiciona como el segundo sector más combativo (18,03\%), secundado por el sector ciudadano y en mayo-junio se iguala con el vecinal con un $14,28 \%$. De todo ello se desprende la idea de que la protesta temática, especialmente obrera y estudiantil, se perpetúa en el tiempo, mientras que en un plano secundario no exento de excepciones asoma la reivindicación vecinal y ciudadana.

\subsection{Los formatos del repertorio}

Desde el análisis cualitativo se han estudiado en prensa los formatos del repertorio de la protesta empleados por la sociedad civil. Cada sector social suele expresarse a través de estos formatos de modo más o menos constante. Por lo tanto, tomando en consideración el grado de valor/noticia que supone el conflicto, hallamos sectores que adquieren un mayor o menor protagonismo en la prensa. Mientras que el sector cultural-artístico expone su contrariedad de forma sólida mediante el formato discurso $(95,38 \%)$ y muy raramente recurre a las manifestaciones $(4,61 \%)$, el sector obrero se expresa fundamentalmente a través de formatos desarrollados en la calle, en huelgas $(41,68 \%)$ y manifestaciones $(28,0 \%)$ y, en menor medida, se vale de las asociaciones con un $10,52 \%$. Los sectores estudiantil, vecinal y ciudadano ocupan una horquilla intermedia entre los sectores citados debatiéndose entre acciones todo tipo. El caso más claro lo representa el sector ciudadano que se expresa equitativamente a través de manifestaciones $(45,08 \%)$ y de discursos $(46,72 \%)$. El sector vecinal emplea discursos $(37,25 \%)$, aunque acude de forma usual a las manifestaciones $(43,13 \%)$. También son las manifestaciones $(34,07 \%)$ el formato al que acuden más los estudiantes, seguido de los discursos $(31,48 \%)$ y de las asociaciones $(6,66 \%)$.

Los formatos evolucionan con el tiempo como demuestra que, conforme avanza la transición, se emplea a nivel general un menor número de manifestaciones. Este formato es muy recurrente en enero y febrero de 1976 con un $27,54 \%$, no obstante, desciende de forma considerable en los meses de mayo y junio $(5,90 \%)$ para continuar creciendo en los meses de verano. A partir de octubre, su uso cae paulatinamente con un breve repunte en enero-febrero de $1977(9,50 \%)$ y una rotunda bajada en mayo-junio $(0,98 \%)$ cuando alcanza sus valores mínimos. La desnivelación es la característica más resaltable del formato huelga, que si en noviembre-diciembre de 1975 registra un 1,83\%, en enero-febrero de 1976 alcanza el 36,99\%, siendo la mayor subida que experimenta un formato, a lo que debemos añadir el escaso intervalo de tiempo en que tiene lugar. Este porcentaje se sostiene en marzo-abril con una bajada $(20,51 \%)$, pero a partir del mes de mayo se emplea irregularmente con ascensos entre 
noviembre de 1976 y febrero de 1977 y descensos en marzo y abril (2,93\%); en el último bimestre analizado vuelve a subir al 5,12\%.

Las asociaciones comparten con las huelgas su carácter vacilante. Como ellas, asisten a un espectacular aumento desde los últimos meses de 1975 (1,13\%) hasta enero y febrero de $1976(18,18 \%)$ para experimentar subidas y bajadas constantes el resto del año. La etapa decreciente comienza en enero-febrero de 1977 y culmina en mayo-junio con un 6,81\%. Los discursos son, por el contrario, el formato que cuenta con mayor estabilidad en el proceso en dos momentos álgidos coincidentes con las oleadas de protesta de enero y febrero de 1976 con un 18,29\% y de enero y febrero de 1977 con un $17,66 \%$.

\subsection{Los niveles de conflictividad}

Dado que los formatos manifestaciones $(31,02 \%)$ y huelgas $(27,77 \%)$ representan casi el $60 \%$, frente a los discursos $(32,24 \%)$ y las asociaciones $(8,95 \%)$, podemos afirmar que, en términos generales, la conflictividad se sitúa en el nivel A (manifestaciones y huelgas), con la matización de que éstos prevalecen a lo largo de año 1976, mientras que los de nivel B (discursos y asociaciones) son más frecuentes en la prensa en los primeros seis meses de 1977.

Si nos detenemos en el proceso, la transición se inicia con el uso de formatos de ambos niveles, siendo levemente más altos los de nivel A. Nos encontramos, por tanto, ante un equilibrio dialógico y callejero con el empleo de discursos y manifestaciones en un 45\%. Entre enero y mayo de 1976 se recrudece la discordia. La correlación apunta a una preeminencia clara de formatos de nivel A en torno al 70-75\% sobre los de nivel B (25-30\%). En enero-febrero, los periódicos publican una gran cantidad de textos que incluyen formatos de nivel A, huelgas $(38,99 \%)$ y manifestaciones $(32,43 \%)$, que crecen en los meses posteriores, así en marzo y abril las huelgas alcanzan el $42,74 \%$.

En los meses de mayo y junio se produce un punto de inflexión. Los formatos dialógicos obtienen una ligera ventaja por la subida de discursos al 33,33\% y de asociaciones al 17,39\%, equiparándose ambos niveles. A partir de julio y hasta final de año se descubre un crecimiento inversamente proporcional. Los formatos dialécticos y asociativos disminuyen a la par que aumentan los de impacto callejero, de este modo las manifestaciones acaparan el 40-44\%, aunque los discursos consiguen en julio y agosto el 38,88\% y en septiembre el 27,38\%. El 31,76\% de discursos se aproxima al 34,11\% de las huelgas como formato de nivel A más elevado a finales de año.

Los meses de enero-febrero de 1977 son testigos de que el impacto reprobatorio se aminora en la calle por la formidable subida del formato discurso que alcanza el $46,66 \%$. Esto es más visible en marzo y abril donde los formatos de nivel $\mathrm{B}$ con un $65 \%$ sobrepasan a los de nivel A con un 35\%, especialmente favorecido por la subida de los discursos en torno al 50\% y de las asociaciones con un 16,39\%. Sin embargo, el aumento de las huelgas $(33,33 \%)$ hace que se reduzcan las distancias entre los formatos de ambos niveles en el último bimestre. 


\section{A modo de conclusión}

La prensa de la transición democrática española sirve de plataforma a la protesta social para ampliar su impacto callejero en la escena pública a sabiendas de que el conflicto asume el valor/noticia en un marco legislativo más permisivo con la expresión reivindicativa. El antiguo repertorio de la protesta (asambleas, paros, huelgas, manifestaciones, etc.) es recurrido por los ciudadanos que demandan libertades y cambios democráticos con ciertas adaptaciones contextuales.

La mediación de la prensa en el proceso democratizador está en consonancia con la mediatización de la protesta. Podemos entender de este modo el desarrollo de la protesta social en medios de distintas líneas ideológicas y editoriales como la expresión de una demanda generalizada de las propias empresas periodísticas. Un ejemplo de mediatización de la prensa es la constatación de la apariencia de legalización del repertorio y la reorientación de la protesta hacia formatos dialógicos y asociacionistas como originadores de valor/noticia, lo que revela en última instancia su rol mediador en la relación entre la sociedad y la clase política.

La prensa como plataforma y la sociedad civil como elemento de presión así concebidos constituyen un tándem indispensable para la consecución del logro democrático que complementa la noción de historiadores y sociólogos sobre la sociedad movilizada, si bien en la prensa sólo es posible referirnos a un resurgimiento ciudadano en la medida en la que protagoniza activamente los textos que tratan el tema de la protesta.

\section{Bibliografía}

ARÓSTEGUI, J. (2000). La Transición (1975-1982). Madrid: Acento.

ATTILI CARD AMONE, A. (2004). "Ciudadanía, sociedad civil y la redefinición de los espacios públicos". En Revista de Estudios Políticos (Nueva Época), n ${ }^{\circ} 126$, Madrid: Centro de Estudios Constitucionales. p. 131-150.

BARRERA, C. (1995). Sin mordaza. Veinte años de prensa en democracia. Madrid: Temas de hoy.

CARRILLO-LINARES, A. (2006). "Movimiento estudiantil antifranquista, cultura política y transición política a la democracia". En Pasado y Memoria. Revista de Historia Contemporánea, $\mathrm{n}^{\circ} 5$, Alicante: Universidad de Alicante, Departamento de Humanidades Contemporáneas. p. 149-172.

DE ZAN, J. (2006). "Los sujetos de la política. Ciudadanía y Sociedad Civil". En Tópicos, $\mathrm{n}^{\mathrm{o}}$ 14. Disponible en: http://www.scielo.org.ar/scielo.php?script=sci_ arttext\&pid=S1666-485X2006000100005_27-12-2012].

GOMIS, L. (1987). El medio "media". La función política de la prensa. Barcelona: Mitre.

HABERMAS, J. (1998). Facticidad y validez. Sobre el Derecho y el Estado democrático de derecho en términos de teoría del discurso. Madrid: Trotta. 
JAIME-JIMÉNEZ, O.; REINARES, F. (1998). "The policing of social protest in Spain: from Dictatorship to Democracy". En DELLA PORTA, D.; REITER, H. (eds.) (1998). Protest policing in contemporary democracies. Minnesota: Minnesota University Press. p. 166-187.

KÖHLER, H. D. (1995). El movimiento sindical en España. Transición democrática. Regionalismo. Modernización económica. Madrid: Fundamentos.

LINZ, J. J. (1992). "La transición a la democracia en España en perspectiva comparada”. En COTARELO, R. (ed.) (1992). Transición politica y consolidación democrática. España 1975-1986. Madrid: Centro de Investigaciones Sociológicas. p. 431-460.

LÓPEZ CANTOS, F. J. (2006). Formación de capital social en democracia. Sociedad civil y modelos comunicativos. En Global Media Journal México, no 3, vol. 6. Disponible en: http://gmje.mty.itesm.mx/lopez_cantos.htm [18-12-2012].

LÓPEZ PINTOR, R. (1982). La opinión pública española: del franquismo a la democracia. Madrid: Centro de Investigaciones Sociológicas.

MARTÍN GARCÍA, O. (2010). “Crisis del franquismo, conflictividad social y cambio democrático en España. Un análisis desde las fuentes diplomáticas británicas". En LEMUS, E.; ROSAS, F.; VARELA, R. (coords.) (2010). El fin de las dictaduras ibéricas (1974-1978). Sevilla: Centro de Estudios Andaluces. p. 135-152.

O’DONNEL, G.; SCHMITTER, P. C. (1986). Transitions from Authoritarian Rule: Tentative Conclusions. Baltimore: Johns Hopkins University Press.

PALACIO ATARD, V. (1989). Juan Carlos I y el advenimiento de la democracia. Madrid: Espasa Calpe.

PÉREZ DÍAZ, V. (1987). El retorno de la sociedad civil. Respuestas sociales a la transición política, la crisis económica y los cambios culturales de España 19751985. Madrid: Instituto de Estudios Económicos.

PÉREZ LEDESMA, M. (2006). “"Nuevos' y 'viejos' movimientos en la transición”. En MOLINERO RUIZ, C. (coord.) (2006). La Transición, treinta años después. Madrid: Península. p. 117-151.

PRESTON, P. (1986). El triunfo de la democracia en España, 1969-1982. Barcelona: Plaza \& Janés.

QUIROSA-CHEYROUZE y MUÑOZ, R. (2011). "El protagonismo de la sociedad en la conquista de la democracia”. En QUIROSA-CHEYROUZE y MUÑOZ, R. (ed.) (2011). La sociedad española en la transición. Los movimientos sociales en el proceso democratizador. Madrid: Editorial Biblioteca Nueva. p. 13-28.

SASTRE GARCÍA, C. (1997). "La transición política en España: una sociedad desmovilizada". En Revista Española de Investigaciones Sociológicas, n ${ }^{\circ}$ 80, Madrid: Centro de Investigaciones Sociológicas. p. 33-68.

SAZ CAMPOS, I. (2010). "La lucha por la libertad en España desde una perspectiva comparada (1962-1977)”. En NAVAJAS ZUBELDÍA, C.; ITURRIAGA BARCO, D. (coord.) (2010). Novísima: II Congreso Internacional de Historia de Nuestro Tiempo. Logroño: Universidad de La Rioja. p. 71-80.

SECO SERRANO, C. (1991). "La transición a la democracia (1975-1982)". En DOMÍNGUEZ ORTIZ, A. (dir.) (1991). Historia de España. El régimen de 
Franco y la transición a la democracia (de 1939 a hoy). Barcelona: Planeta. p. 249-463.

SINOVA, J. (1989). La censura de prensa durante el franquismo (1936-1951). Madrid: Espasa Calpe.

SOTO, A. (1998). La transición a la democracia. España 1975-1982. Madrid: Alianza.

TARROW, S. (2004). Poder en movimiento. Los movimientos sociales, la acción colectiva y la política. Madrid: Alianza Editorial.

TILLY, C. (1978). From Mobilization to Revolution. Reading: Addison-Wesley.

TUSELL, J.; SOTO, A. (eds.) (1996). Historia de la transición (1975-1986). Madrid:

Alianza.

\section{La autora}

Sandra Méndez Muros es Doctora en Periodismo con la tesis Tratamiento periodístico del tardofranquismo y de la transición democrática en la prensa sevillana (Abc y El Correo de Andalucía: 1964-1978). Profesora de Historia del Periodismo Español en la Facultad de Comunicación de la Universidad de Sevilla y del Título de Experto Universitario en Periodismo Local, Medio Ambiente, Sociedad Civil e Innovación. Autora de los libros Sevilla y el tardofranquismo según $A B C$ y El Correo (2007) y Prensa y acontecimiento político en el cambio de siglo (1998-2002) (2012), sus estudios se centran en el análisis de la sociedad civil en relación con la Historia y las Tecnologías del Periodismo. 